\title{
SURGICAL SITE INFECTION RATE AND RISK FACTORS AMONG OBSTETRIC CASES OF JIMMA UNIVERSITY SPECIALIZED HOSPITAL, SOUTHWEST ETHIOPIA
}

\author{
Demisew Amenu $^{* 1}$, Tefera Belachew ${ }^{2}$, Fitsum Araya ${ }^{1}$
}

\begin{abstract}
BACKGROUND: Surgical Site infections are the second most frequently reported infections of all nosocomial infections among hospital patients. Among surgical patients in obstetrics, Surgical Site Infections were the most common nosocomial infections and the rate is higher in sub-Saharan Africa. There has not been a study which documented the extent of the problem in the study area; hence the objective of this study was to determine the surgical site infection rate among women having surgery for delivery in obstetrics of Jimma University Specialized Hospital (JUSH) from April 1, 2009 to March 31, 2010.
\end{abstract}

METHODS: A prospective descriptive study design was conducted with the aim of determining the surgical site infection rate on all 770 women who had surgery for delivery from April 1, 2009 to March 31, 2010 in obstetric ward of the Hospital. Data on history of the patient, patient specific demographic information on potential risk factors and the occurrence of Surgical Site infections in the first 30 days following surgery were collected using pretested data collection form. In addition, relevant data were also abstracted from the operation logbook of the cases. Then data were cleaned, edited and fed to computer and analyzed using SPSS for window version 16.0. Finally Statistical test for significance was employed using chi-squared $\left(X^{2)}\right.$ where appropriate at $5 \%$ level of significance.

RESULTS: The mean $( \pm S D)$ of the subjects' age was $26( \pm 7)$ years and the majority of the women were from the rural areas (72.7\%). The overall surgical site infection rate was $11.4 \%$. Of those who had surgical site infections, $64.8 \%$ had clean-contaminated wound and $35.2 \%$ had contaminated /dirty wounds. Wound class at time of surgery has a statistically significant association with Surgical Site infections $(p<0.001)$.The Surgical Site infections rate was similar for cesarean section and abdominal hysterectomy but higher for destructive delivery under direct vision. Majority of the operations were made for emergency Obstetric conditions (96.6\%) and the Surgical Site Infections rate was two times higher compared to that of elective surgery. Chorioamnionitis, presence of meconium, large intraoperative blood loss and Perioperative blood transfusion were associated with increased severity of SSIs with $p<0.001$. Absence of antenatal care follow up was also associated with increased severity of Surgical Site Infections.

CONCLUSION: it has been revealed that Surgical Site Infections rates are higher than acceptable standards indicating the need for improving Antenatal care, increasing the number of skilled birth attendants at the local clinics, increasing basic and comprehensive emergency obstetric care services, applying improved surgical techniques and improving infection prevention practices to decrease infection rate to acceptable standard.

KEYWORDS: surgical site infection, antenatal care, chorioamnionitis, meconium.

\footnotetext{
${ }^{1}$ Department of Gynecology and Obstetrics, Jimma University

Department of Population and Family Health, Jimma University

*Corresponding Author, E-mail:demisew.amenu@ju.edu.et
} 


\section{INTRODUCTION}

Infection in obstetrics accounts for the second most common cause of maternal mortality next to post partum hemorrhage. Among surgical patients in obstetrics, surgical site infections (SSIs) are the most common nosocomial infections, accounting for $38 \%$ of hospital acquired infections (1). According to the Center for Disease Control and prevention (CDC) SSIs are classified as being either incisional or organ space that must develop within 30 days of operation. Incisional SSIs are further divided into those involving only skin and subcutaneous tissue (superficial incision SSI) and those involving the deeper soft tissue of the incision (deep incisional SSI). Organ/space SSIs involve any part of the anatomy (e.g. organ/space) other than incisional body wall layers that was opened or manipulated during an operation (2-3). The CDC definitions of SSIs have been applied consistently by surveillance and surgical personnel in many settings and currently are the de facto national standards (4-5).

Operations in obstetrics involve some degree of bacterial contamination, and are classified as 'clean-contaminated' cases, even when the patient has no preoperative symptoms of active infection (6). Pregnant women are at risk of infection during labor and delivery; most infections of the female pelvic organs occur when normal flora of the female genital or gastrointestinal tract contaminate the normally sterile amniotic fluid and uterus (7).

The widespread use of antibiotic prophylaxis has reduced but not eliminated serious postoperative infections; the average expected SSIs rate being 3-15\% after cesarean section. These rates are increased in the presence of other risk factors such as gross contamination of the operative site, prolonged and premature rupture of membranes, obstructed labor, chorioamnionitis, massive obesity, prolonged operative time, emergency operations, altered immune status, which are common in resource poor countries like Ethiopia (8). Other factors related to the skill of the surgeon like: poor surgical techniques, inadequate hemostasis, and presence of dead space predispose to greater wound infection. On top of these medical illnesses during pregnancy and malnutrition also contribute much to the problem (9). Even though studies are limited in Ethiopia, SSIs as the commonest cause of nosocomial infection in obstetrics, even in this modern era, is still a major public health problem in developing countries (10-11).

Despite every effort to maintain asepsis, almost all surgical sites are contaminated with bacteria, but the degree of contamination and the risk of subsequent infection vary among patients. Based on the degree of contamination, wounds are classified as clean, clean-contaminated, contaminated, dirty or infected and many studies have revealed that the risk of infection increase with degree of contamination. In developing countries, especially in sub-Saharan Africa this figure is higher where on average wound infection rates in these countries are twice or three times higher than developed countries (11-13).

Different studies have shown that the omission or untimely use of single dose Perioperative antimicrobial prophylaxis has been associated with increased incidence and severity of postoperative SSIs (13-14).

Surgical site infection rate per 100 operations was reported to be $2.1 \%$ for clean, $3.3 \%$ for cleancontaminated, $6.4 \%$ for contaminated and $7.1 \%$ for dirty or infected wounds. Because the vagina is entered during hysterectomy and cesarean, even an uninfected one is classified as a cleancontaminated operation $(13,15)$.

Although high incidence of SSI is suspected in Ethiopia, the magnitude of the problem is not known, especially for obstetrics. However, the overall SSI rate was reported to be $21 \%$ in general surgical wards of teaching hospitals. In addition, previous study to assess nosocomial infections in the country showed that surgical site infection was the commonest cause of nosocomial infection in Obstetrics and Gynecology than in general surgical wards. However, no study was done so far to assess the magnitude of the problem in Ethiopian Obstetric wards (13, 16-17).

In other African counties also the SSI rate reported has been is higher than in developed counties - a case in point is a study done in Tanzanian district hospital where the SSI rate reported following cesarean section and hysterectomy were $24 \%$ and $36 \%$, respectively. And according to the CDC's definitions, $38.2 \%$ of

the patients had a superficial, $46.5 \%$ had deep, and $15.3 \%$ had an organ/space SSI. Of these $21 \%$ were 
identified after discharge and 3\% were readmitted (18).

It has been documented that the risk of SSI doubles with each additional operative hour depending on the operative procedures being performed. Studies have also shown that meticulous surgical techniques play a critical role in the prevention of surgical site infections (1921). Furthermore Meconium-stained amniotic fluid is also associated with increased peripartum infection, independent of other risk factors for infection and thick meconium had higher infection rates than clear amniotic fluid (44\% versus 13\%) (22).

\section{PATIENTS AND METHODS}

The study was conducted in the Oromia region, Jimma zone, Jimma City, at Jimma University Specialized Hospital Obstetrics and Gynecology department, Obstetrics ward from April 1, 2009March 31, 2010. The Hospital is one of the oldest teaching hospitals in the country and the department provides various services for the people living in Jimma zone and serves as a referral hospital in the South-Western Ethiopia. The department has three wards (Maternity, Labor and Gynecology) and outpatient clinics (Antenatal care follow-up, family planning and gynecology).

A prospective descriptive study design was used to follow post operative cases which include Hysterectomy, Cesarean section, and Destructive delivery under direct vision and all obstetric patients operated during the study period were considered eligible for this study. Patients who died before the third post operative days were excluded.

A structured interviewer administered English version data collection format was used translating to the local language to capture data for those who developed surgical site infections both from the records and from the study participants. Five Obstetrics and Gynecology residents were trained on how to detect SSI with demonstration on few cases using the CDC's criteria.

Patients were followed for the development of SSI by the resident and surgical sites were evaluated on the third, fifth

postoperative day and on the day of discharge. All suspected surgical sites were evaluated irrespective of the day of operation, until it healed or progressed to infection. Patients who developed infection after discharge were identified from outpatient and follow up clinics.

Finally the collected data were cleaned, fed to computer and analyzed using SPSS version 16.0 for windows and interpretation, discussion and recommendation were made based on the findings.

An official letter was obtained from the Ethical Review Board of University to conduct this research and get consent from each patient. The patients were told about the objectives and benefits of the study and after having verbal consent from the patient with SSI, data collectors took history of the patient, patient specific demographic characteristics and information on potential risk factors of SSI, recorded on the day of surgery from patient record and the responsible surgeon, when necessary.

The outcome of this study has been communicated to the Department and Hospital's clinical director.

For this research the following operational definitions were used: -

Surgical Site Infection is classified as superficial, deep and organ/space infection which occurs within 30 days after the operation.

Superficial SSI is infection which involves only skin and subcutaneous tissue of the incision and at least one of: -

1. purulent drainage with or without laboratory confirmation,

2. organism isolated from superficial incision,

3. presence of sign and symptoms of infection at the site,

4. Diagnosis of SSI by physician/surgeon where Stitch abscess, Infection of an episiotomy are not included.

Deep Incisional SSI: - is infection involving deep soft tissues (e.g., fascial and muscle layers) of the incision and at least one of:

1. Purulent drainage from the deep incision,

2. A deep incision spontaneously dehisces or is deliberately opened by a surgeon when the patient has at least one of the following signs or Symptoms: fever $\left(>38^{\circ} \mathrm{C}\right)$, localized pain, or tenderness, unless site is culture-negative, an abscess or other evidence of infection involving the deep incision,

3. Diagnosis of a deep incisional SSI by a surgeon or attending physician. 
- Infection that involves both superficial and deep incision sites are reported as deep incisional SSI and an organ/space SSI that drains through the incision as a deep incisional SSI.

Organ/Space SSI is infection which involves any part of the anatomy (e.g., organs or spaces), other than the incision, which was opened or manipulated during an operation and at least one of the following:

1.Purulent drainage from a drain that is placed through a stab wound into the organ/space,

2. Organisms isolated from an aseptically obtained culture of fluid or tissue in the organ/space,

3. An abscess or other evidence of infection involving the organ/space that is found on direct examination, during re-operation, or by histopathologic or radiologic examination,

4.Diagnosis of an organ/space SSI by a surgeon or attending physician

\section{Class I/Clean:}

- An uninfected operative wound in which no inflammation is encountered and the respiratory, alimentary, genital, or uninfected urinary tract is not entered. In addition, clean wounds are primarily closed and, if necessary, drained with closed drainage. Operative incisional wounds that follow non-penetrating (blunt) trauma should be included in this category if they meet the criteria.

\section{Class II/Clean-Contaminated:}

- An operative wound in which the respiratory, alimentary, genital, or urinary tracts are entered under controlled conditions and without unusual contamination. Specifically, operations involving the biliary tract, appendix, vagina, and oropharynx are included in this category, provided no evidence of infection or major break in technique is encountered

\section{Class III/Contaminated:}

- Open, fresh, accidental wounds. In addition, operations with major breaks in sterile technique (e.g., open cardiac massage) or gross spillage from the gastrointestinal tract, and incisions in which acute, nonpurulent inflammation is encountered are included in this category.

\section{Class IV/Dirty-Infected:}

- Old traumatic wounds with retained devitalized tissue and those that involve existing clinical infection or perforated viscera. This definition suggests that the organisms causing postoperative infection were present in the operative field before the operation.

Prophylactic antibiotic: refers to a very brief course of an antimicrobial agent initiated just before an operation begins with an attempt to sterilize tissues, but a critically timed adjunct used to reduce the microbial burden of intraoperative contamination to a level that cannot overwhelm host defenses.

Excellent surgical technique: Such technique include maintaining adequate hemostasis while preserving adequate blood supply, preventing hypothermia, gently handling tissues, avoiding inadvertent entries into a hollow viscus, removing devitalized tissues, using drains and suture materials, preferably monofilaments, obliterating dead space, and appropriately managing the post operative incision

\section{Physical status classification, American Society of Anesthesiologists (ASA)-}

\section{Code Patient's Preoperative Physical Status}

I. Normally healthy patient

II. Patient with mild systemic disease

III. Patient with severe systemic disease that is not incapacitating

IV. Patient with an incapacitating systemic disease that is a constant threat to life

V. Moribund patient who is not expected to survive for 24 hours with or without operation 


\section{RESULTS}

Among the total 778 mothers operated for delivery during the study period in Jimma University Specialized Hospital Obstetrics ward, 8 were excluded as they died within the first two days of operation; and the remaining 770 were analyzed. The age of the women ranged from 15 to 40 years with a mean of $26( \pm 7)$ years and $67(76.1 \%)$ percent were between the age ranges of 20 to 34 years. Seventy three percent were from rural areas, $43(48.9 \%)$ Muslims, 55 (62.5\%) Oromo, 60 $(68.2 \%)$ housewife, $59(67.1 \%)$ illiterate and 44 $(50.0 \%)$ were from low monthly family income (Table 1).

TABLE 1. Socio-demographic characteristics of women who developed surgical site infection after surgery for delivery in obstetrics ward of JUSH, April 1, 2009 - March 31, 2010.

$\begin{array}{llcc}\text { Socio-demographic character of women } & \text { Frequency (N= 88) } & \text { Percent } \\ \text { Age in years } & \leq 19 & 8 & 9.1 \\ & 20-34 & 67 & 76.1 \\ \text { Ethnicity } & \geq 35 & 13 & 14.8 \\ & \text { Oromo } & 55 & 62.5 \\ & \text { Amhara } & 18 & 20.5 \\ & \text { Tigre } & 2 & 2.3 \\ & \text { Guragie } & 4 & 4.5 \\ \text { Religion } & \text { Dawro } & 9 & 10.2 \\ & \text { Muslim } & 43 & 48.9 \\ \text { Occupation } & \text { Orthodox Christian } & 38 & 43.2 \\ & \text { Protestant } & 7 & 8.0 \\ & \text { House wife } & 60 & 68.2 \\ & \text { Civil servant } & 8 & 9.1 \\ & \text { Merchant } & 12 & 13.6 \\ & \text { Farmer } & 7 & 8.0 \\ & \text { Others } & 1 & 1.1 \\ \text { Educational status } & \text { Illiterate } & 59 & 67 \\ & \text { Read and write only } & 6 & 6.8 \\ & \text { Grade 1-8 } & 10 & 11.4 \\ & \text { Grade 9-12 } & 8 & 9.1 \\ & >12 & 5 & 5.7 \\ \text { Family (birr/mont) } & \text { Married } & 85 & 96.6 \\ & \text { Divorced } & 3 & 3.4 \\ \text { Adress } & \text { 501- 1000 } & 44 & 50.0 \\ & \geq 1001 & 33 & 37.5 \\ \text { Marital status } & \text { Urban } & 11 & 12.5 \\ & \text { Rural } & 24 & 27.3 \\ & & 64 & 72.7\end{array}$

The overall SSI rate was $11.4 \%$ among the total 770 women studied, Cesarean Section accounted for $66(75.0 \%)$ followed by abdominal hysterectomy $19(21.6 \%)$ and the surgical site infections rate was almost similar $(11.4 \%$ vs.

$10.6 \%$ ), respectively. The SSI rate for destructive delivery under direct vision was found to be higher (3 out of 10) (Table 2). Ninety six percent of the operations were emergency and $3(3.4 \%)$ were elective (figure 1 and Table 5). 
TABLE 2. Surgical Site Infection rate by types of operation and age of the mothers having surgery for delivery in obstetrics ward of JUSH, April 1, 2009 - March 31, 2010.

\begin{tabular}{lccc}
\hline Variables & $\begin{array}{c}\text { Number } \\
(\mathbf{n = 7 7 0 )}\end{array}$ & $\begin{array}{c}\text { Frequency } \\
\text { Infected }\end{array}$ & $\begin{array}{c}\text { Percent } \\
\text { infected }\end{array}$ \\
\hline Age in years & & & \\
$\leq 19$ & 69 & 8 & 11.6 \\
$20-34$ & 585 & 67 & 11.5 \\
$\quad 116$ & 13 & 11.2 \\
$\quad 35$ & & & \\
Type of operation & 580 & 66 & 11.4 \\
$\quad$ Cesarean section & 180 & 19 & 10.6 \\
$\quad$ Abdominal hysterectomy & 3 & 30.0 \\
$\quad$ Destructive delivery under direct vision & 10 & 3 & \\
\hline
\end{tabular}

Concerning the obstetric conditions of mothers, 32 (36.4 \%) were Para I, 45 (51.1\%) had no antenatal care follow-up, $77(87.5 \%)$ operated at term (using either LMP or symphysis fundal height measurement) and 74 (84.1 of ASA class I \%) (Table 3).

TABLE 3. Distributions of SSIs among women having surgery for delivery in Obstetrics ward of JUSH by obstetric variables, April 1, 2009- March 31, 2010.

\begin{tabular}{|c|c|c|c|}
\hline Obstetrics variables & Category & $\begin{array}{l}\text { Frequency } \\
(\mathrm{N}=\mathbf{8 8})\end{array}$ & Percent \\
\hline \multirow[t]{3}{*}{ Parity } & $\mathrm{I}$ & 32 & 36.4 \\
\hline & II-IV & 31 & 35.2 \\
\hline & $\geq \mathrm{V}$ & 25 & 28.4 \\
\hline \multirow[t]{2}{*}{ Antenatal care follow up } & Yes & 43 & 48.9 \\
\hline & No & 45 & 51.1 \\
\hline \multirow[t]{2}{*}{ Duration of pregnancy at time of surgery } & Preterm & 11 & 12.5 \\
\hline & Term & 77 & 87.5 \\
\hline \multirow[t]{2}{*}{ ASA class before operation surgery } & $\mathrm{I}$ & 74 & 84.1 \\
\hline & II & 14 & 15.9 \\
\hline \multirow{2}{*}{$\begin{array}{l}\begin{array}{l}\text { Thickness of subcutaneous tissue in } \\
\text { centimeters }\end{array}\end{array}$} & $<2$ & 69 & 78.4 \\
\hline & $\geq 2$ & 19 & 21.6 \\
\hline
\end{tabular}

ASA = American society of anesthesiologist, physical classification of preoperative patients

For ninety five percent of women the SSIs were detected before discharge and cases detected after discharge 4 (4.5\%) were not readmitted. The mean postoperative day SSIs detected and the mean number of additional postoperative day of hospital stay due to SSIs were 6.5 (3- 14 days) and 12.3 (460 days), respectively. Distribution of the type of SSIs showed, superficial SSI 59 (67\%) followed by deep SSI $19(21.6 \%)$ and organ/space SSI $10(11.4 \%)$. Sixty five percent of women who developed SSIs had clean contaminated wounds at the time of surgery and the rest had contaminated or dirty wounds. Wound class at the time of surgery had a strong statistical association with the severity of SSIs $(p<0.001)$. Those who had contaminated/dirty wounds at the time of surgery had more severe type of surgical site infections (deep and organ/space), more likely to have relaparotomy, longer postoperative hospital stay and higher maternal mortality (Table 5, 6). On the other hand, women who underwent emergency surgery had two times increased risk of surgical site infections rate than those of elective ones (11.9\% vs. $5.4 \%$ ) (Table 4$)$. 
TABLE 4. Outcomes of mothers with SSIs following surgery for delivery in Obstetrics ward of JUSH, April 1, 2009- March 31, 2010.

\begin{tabular}{lccc}
\hline Variables & Category & $\begin{array}{c}\text { Frequency } \\
(\mathrm{N}=88)\end{array}$ & Percent \\
\hline The time surgical site infection detected & Before discharge & 84 & 95.5 \\
& After discharge & 4 & 4.5 \\
& Superficial & 59 & 67.0 \\
Types of surgical site infections detected & Deep & 19 & 21.6 \\
& Organ /space & 10 & 11.4 \\
Postoperative day SSIs detected & $\leq 7$ & 66 & 75.0 \\
Number of additional hospital stay due to & $8-14$ & 22 & 25.0 \\
SSIs & $\leq 7$ & 29 & 33.0 \\
& $8-14$ & 35 & 38.8 \\
& $15-30$ & 22 & 25.0 \\
\hline
\end{tabular}

Further, more women who didn't have ANC follow up developed more severe type of SSIs than those with ANC follow up $(\mathrm{p}<0.05)$. However, there was no statistically significant association between duration of labor, duration of rupture of membrane and the severity of SSIs (Table 5).

Women with chorioamnionitis at the time of surgery had increased severe form of SSIs ( $p$ $<0.001)$. Also presence of meconium is associated with increased severity of SSIs ( $p<0.009$ ). American Society of Anesthesiologists (ASA) physical status before surgery, thickness of subcutaneous tissue, saline irrigation of wound at the time of incision closure, duration of operation, educational status, family income and the level of postoperative hematocrit had no association with the severity of SSIs in this study (Table 6). Women with intraoperative blood loss of 1,000 $\mathrm{mL}$ and more had a statistically significant increased risk of more severe form of SSIs than women with less blood loss $(p=0.001)$. Women who took blood transfusion during and after the operation were developed more severe SSIs $(p=$ 0.001 ). The mean duration of operation for cesarean section, abdominal hysterectomy and destructive delivery under direct vision was 47 , 90 , and 105 minutes, respectively and the duration of operation in this study had no association with the severity of SSIs $(\mathrm{P}>0.05)$. Among 88 women who developed SSIs, 8 of them died making the case fatality rate of $9 \%$. Even though there is no statistical significant association, all deaths occurred among women from rural areas $(\mathrm{p}=0.06)$. Half of mothers who had relaparotomy for wound dehiscence following SSI died (Table 6). There is no difference between women having ANC follow up or not in terms of maternal outcomes. The maternal mortality rate progressively increases with the class of wounds at the time of surgery. The Odds Ratio between clean-contaminated and contaminated was $6.6(\mathrm{p}=0.01)$.

\section{DISCUSSION}

The rate of surgical site infections (11.4\%) reported in this study may still be underestimated since some post operative patients might be lost from follow-up, which is reported to be as high as $21 \%$ in some studies as compared to $4.5 \%$ in this study.

Eighty nine percent of the infections were confined to the incision site and the rest involved the organ/spaces accessed during operation. This finding is similar with previous studies done in other African country and age is not associated with increased SSIs. Also true for marital status, educational status, and income of the family. The surgical site infection rate in this study is lower than the previous study done in other African country but it is still higher than the standard for developed nations (18). 
TABLE 5. Association of severity of surgical site infections by socio-demographic and obstetric variables among women having obstetric surgery in JUSH, April 1, 2009- March 31, 2010.

\begin{tabular}{|c|c|c|c|c|c|c|}
\hline \multirow[t]{2}{*}{ Variables } & & \multicolumn{3}{|c|}{ *Severity of Surgical site infection } & \multirow[b]{2}{*}{$\begin{array}{c}\text { Total } \\
\text { № },(\%)\end{array}$} & \multirow[b]{2}{*}{ P Value } \\
\hline & & $\begin{array}{c}\text { Less } \\
\text { severe }\end{array}$ & Severe & $\begin{array}{c}\text { More } \\
\text { severe }\end{array}$ & & \\
\hline \multirow{3}{*}{$\begin{array}{l}\text { Place of residence } \\
\text { of the women }\end{array}$} & Urban & $21(87.5)$ & $3(12.5)$ & $0(0.0)$ & $24(27.3)$ & \multirow{3}{*}{$<0.02$} \\
\hline & Rural & $38(59.4)$ & $16(25.0)$ & $10(15.6)$ & $64(72.7)$ & \\
\hline & Total & $59(67.0)$ & $19(21.6)$ & $10(11.4)$ & $88(100.0)$ & \\
\hline \multirow{3}{*}{$\begin{array}{l}\text { Circumstance of } \\
\text { surgery }\end{array}$} & Emergency & $56(65.9)$ & $19(22.3)$ & $10(11.8)$ & $85(96.6)$ & \multirow{3}{*}{0.4} \\
\hline & Elective & $3(100)$ & $0(0.0)$ & $0(0.0)$ & $3(3.4)$ & \\
\hline & Total & $59(67.0)$ & $19(21.6)$ & $10(11.4)$ & $88(100)$ & \\
\hline \multirow[t]{3}{*}{ ANC follow up } & Yes & $34(79.0)$ & $7(16.4)$ & $2(4.6)$ & $43(48.9)$ & \multirow{3}{*}{0.04} \\
\hline & No & $25(55.6)$ & $12(26.7)$ & $8(17.7)$ & $45(51.1)$ & \\
\hline & Total & $59(67.0)$ & $19(21.6)$ & $10(11.4)$ & $88(100.0)$ & \\
\hline \multirow{3}{*}{$\begin{array}{l}\text { Duration of labor } \\
\text { before } \\
\text { operation(hr) }\end{array}$} & $\leq 24$ & $35(70.0)$ & $11(22.0)$ & $4(8.0)$ & $50(60.2)$ & \multirow{3}{*}{0.3} \\
\hline & $\geq 25$ & 19(57.6) & $8(24.2)$ & $6(18.2)$ & $33(39.8)$ & \\
\hline & Total & $54(65.0)$ & $19(22.9)$ & $10(12.1)$ & $83(100.0)$ & \\
\hline \multirow{3}{*}{$\begin{array}{l}\text { Duration of rupture } \\
\text { of membranes(hr) }\end{array}$} & $\leq 12$ & $27(79.4)$ & $5(14.7)$ & $2(5.9)$ & $34(41.0)$ & \multirow{3}{*}{0.07} \\
\hline & $\geq 13$ & $27(55.1)$ & $14(28.6)$ & $8(16.3)$ & $49(59.0)$ & \\
\hline & Total & $54(65.1)$ & $19(22.9)$ & $10(12.0)$ & $83(100.0)$ & \\
\hline \multirow[t]{3}{*}{ Chorioamnionitis } & Yes & $14(40.0)$ & $13(37.1)$ & $8(22.9)$ & $35(39.8)$ & \multirow{3}{*}{$<0.001$} \\
\hline & No & $45(84.9)$ & $6(11.3)$ & $2(3.8)$ & $53(60.2)$ & \\
\hline & Total & $59(67.0)$ & $19(21.6)$ & $10(11.4)$ & $88(100.0)$ & \\
\hline \multirow[t]{3}{*}{ Meconium } & Yes & $29(54.7)$ & $15(28.3)$ & $9(17.0)$ & $53(60.2)$ & \multirow{3}{*}{0.009} \\
\hline & No & $30(85.7)$ & $4(11.4)$ & $1(2.9)$ & $35(39.8)$ & \\
\hline & Total & $59(67.0)$ & $19(21.6)$ & $10(11.4)$ & $88(100.0)$ & \\
\hline \multirow{3}{*}{$\begin{array}{l}\text { Volume of intra op } \\
\text { blood loss }\end{array}$} & $\leq 1000 \mathrm{~mL}$ & $51(76.1)$ & $14(20.9)$ & $2(3.0)$ & $67(76.1)$ & \multirow{3}{*}{$<0.001$} \\
\hline & $\geq 1001 \mathrm{~mL}$ & $8(38.1)$ & $5(23.8)$ & $8(38.1)$ & $21(23.9)$ & \\
\hline & Total & $59(67.0)$ & $19(21.6)$ & $10(11.4)$ & $88(100.0)$ & \\
\hline \multirow{3}{*}{$\begin{array}{l}\text { Peri-operative } \\
\text { blood transfusion }\end{array}$} & Yes & $6(28.6)$ & $8(38.1)$ & $7(33.3)$ & $21(23.9)$ & \multirow{3}{*}{$<0.001$} \\
\hline & No & $53(79.1)$ & $11(16.4)$ & $3(4.5)$ & $67(76.1)$ & \\
\hline & Total & $59(67.0)$ & $19(21.6)$ & $10(11.4)$ & $88(100.0)$ & \\
\hline \multirow[t]{3}{*}{$\begin{array}{l}\text { Wound class at the } \\
\text { time of surgery }\end{array}$} & $\begin{array}{l}\text { Clean- } \\
\text { contaminated }\end{array}$ & $48(84.2)$ & $8(14.0)$ & $1(1.8)$ & $57(64.8)$ & \multirow{3}{*}{$<0.001$} \\
\hline & $\begin{array}{l}\text { Contaminate } \\
\text { d/dirt }\end{array}$ & $11(35.5)$ & $11(35.5)$ & $9(29.0)$ & $31(35.2)$ & \\
\hline & Total & $59(67.0)$ & $19(21.6)$ & $10(11.4)$ & $88(100.0)$ & \\
\hline
\end{tabular}

* Less severe $=$ superficial SSI, Severe $=$ deep SSI, More severe $=$ Organ space SSI

Women from rural areas had more severe form of surgical site infection compared to those form urban $(p=0.02)$. This group of women developed more severe type of infections (deep or organ/space) than those from urban areas, as most of them presented late with prolonged labor and associated chorioamnionitis. Surgical Site Infections where women who underwent emergency surgery had SSIs rate twice as high as those who were operated on elective basis and similar findings have been reported by other studies $(13,15)$.

The severity of SSIs was not related to duration of pregnancy, labor, rupture of membranes and ASA class in this study as all patients were either ASA class I or II. However, prolonged rupture of membrane ( $>12$ hours) has been significantly associated $(\mathrm{P}<0.05)$ with chorioamnionitis which was in turn significantly associated with SSIs $(p<0.001)$. Wound class at 
the time of surgery was found to be associated with development of severe type of surgical site infections $(\mathrm{p}<0.001)$. Similar findings were reported by other studies $(13,15)$.

Women who developed SSIs and had contaminated/dirty wound at the time of surgery were five times more likely to die and also half of women who had re-laparotomy for deep or organ/space SSI died of their disease.

Women with intra-operative blood loss of more than $1000 \mathrm{ml}$ were more likely to have perioperative blood transfusion and had a statistically significant association with increased severity of SSIs $(p<0.001)$. This may be as a result of uncorrected anemia after transfusion with inadequate volume of blood or omission of transfusion in this setting and bacterial contamination of blood products. However, there is currently no scientific basis for withholding necessary blood products from surgical patients as a means of either incisional or organ/space SSI risk reduction (19).

Presence of meconium was strongly associated with increased severe form of SSIs ( $p$ $=0.009$ ). This finding is consistent with the study which showed that presence of thick meconium in amniotic fluid is strongly associated with peripartum and post operative infection including SSIs. These findings revealed that women from rural areas were less likely to have ANC follow up, had prolonged labor, meconium and rupture of membranes. The latter two conditions were associated with chorioamnionitis which was strongly associated with increased risk of surgical site infections (22).

The surgical site infection rate is not affected by age, marital status, educational status, monthly family income, occupation, duration of operation, thickness of subcutaneous tissue, post operative hematocrit and ASA class but significantly affected by address of the patient, ANC follow up, prolonged rupture of membranes, chorioamnionitis, meconium, circumstance of surgery, volume of intra-operative blood loss, perioperative blood transfusion and wound class at time of surgery. However, it is difficult to conclude that the variables which had no association with SSIs are totally not important, as small number of cases were there to show statistical significance. Thus, a further study with extended duration should be conducted to examine their association.

In conclusion, the result obtained for the Surgical Site Infection rate is lower reports from another African countries but still higher than the reports for developed countries. In this study the majority of the subjects $(72.7 \%)$ were from rural areas and had no ANC follow up, were presented with prolonged rupture of membranes, underwent emergency surgeries, had higher SSIs rate and the mortality rate was higher.

Therefore, ANC follow up should be strengthened in the rural areas and availing skilled birth attendants at each health facility in the community so as to detect problems early and apply the basic emergency obstetric care or to refer in time patients to decrease pregnancy complications and emergency obstetric care services should be increased to increase access for the care and decrease delay. In addition, excellent surgical techniques should be applied to reduce SSIs and active surgical site infection surveillance and infection prevention should be established.

\section{ACKNOWLEDGEMENTS}

We would like to acknowledge the study participants, the data collectors and W/o Azeb Mobae for typing the manuscript. Our appreciation also goes to SRP office for its financial and logistic support.

\section{REFERENCES}

1. Morgan AJ, Horan TC, Pearson ML, Silver LC, Jarvis WR. The hospital infection control practices Advisory Committee: A guideline for prevention of surgical site infection. Infect control and hospital epidemiol, 1999; 20 (4):247- 78 .

2. Horan TC, Gaynes RP, Martone WJ, Tarvis WR, Emori TG. CDC definition of nosocomial surgical site infection: a modification of CDC definition of surgical wound infection. Infect control and hospital epidemiol, 1992;13 (10):606-8.

3. Ehrenkranz NJ, Richter EI, Phillips PM, Shultz JM. An apparent excess of operative site infections: analyses to evaluate false 
positive diagnosis. Infect control hospital epidemiol, 1995; 16(12): 712-6.

4. Taylor G, Mckenzie M, Kirkland T, Wiens R. Effect of surgeon's diagnosis on surgical wound infection rates. Am $\mathrm{J}$ infect control 1990; 18(5): 295-9.

5. SHEA, APIC, CDC, SIS. Consensus paper on the surveillance of surgical wound infections. Infect control hospital epidemiol, 1992; 13(10):599-605.

6. John W. Larsen, W. David Hager, Charles H. Livengood, Udo Hoyme. Guideline for the diagnosis, treatment and prevention of post operative infections. Infect dis Obs/Gyn 2003; 11: 65-70.

7. Chris A.Van Beneden, Lauri A.Hicks, Laura E.Riley, Jay Schulkin. Provider knowledge, attitude, practices regarding obstetrics and post surgical gynecologic infections. Infect dis Obs/Gyn, September 2007.

8. L.Raka, D.Zounman. Prevalence of nosocomial infections in high risk units in the university clinical center of Kosovo. Infect control and hospital epidemiol, 2006; 27(4):421-3.

9. Addis Ababa, Ethiopia and Calverton, Maryland, USA: central statistical agency and Marco. Ethiopia Demographic and health survey on nutrition in pregnancy 2005; 163 164.

10. Ado C, Tertuliano A, George, Maria. SSI in university hospital in North east Brazil. Brazil $\mathrm{J}$ infect dis 2005; 9(4):26-30.

11. Daniel A, Zemanuel, Tesfahunegne. Hospital acquired surgical site and catheter related urinary tract infections among patients admitted in Mekele hospital, Mekele, Tigray, Ethiopia. AAU libraries electronic thesis and dissertation, April 23, 2008.

12. WHO, UNICEF, UNFPA and World Bank. Estimates of maternal mortality: a report by WHO, UNICEF, UNFPA and World Bank. Geneva WHO; 2005.
13. Mulat T. Wound infection in Tikur Anbessa hospital, surgical department. Ethiopian med J, 2005; 43(3): 167-174.

14. Cunningham FG, Leveno KJ, Bloom SL, Hanth JC, Gilstrap III L, Wensrom KD. Williams Obstetrics. 22nd edition, 2005.

15. John A.Rock and Howard W.Jones. Te Linde's operative gynecology. 10th edition, 2008.

16. Cuver DH, Horan TC, Gynes RP, et al. Surgical wound infection rates by wound class, operative procedure, and patient risk index NNIS system. Am J med 1991; 91(suppl B):152-7.

17. Kotiso B, Assefa A. Surgical wound infection in a teaching hospital in Ethiopia. East Afr J 1998; 75: 402-405.

18. Jan F, Christoph H, Isaac S, Patience K. Risk factors for SSI in a Tanzanian district hospital: a challenge for the traditional National Nosocomial Infection Surveillance System Index. Infect control and hospital epidemiology 2006; 27 (12): 1401-1404.

19. Haley RW, Culver DH, Morgan WM, White JW, Emori TG, Hooton TM. Identifying patients at high risk of surgical wound infection. A simple multivariate index of patient susceptibility and wound contamination. Am J epidemiol 1985; 121:206-15.

20. Vegas AA, Jodan VM, Garcia ML. Nosocomial infection in surgery wards: A controlled study of increased duration of hospital stay and direct cost of hospitalization. Eur J epidemiol 1993; 9(5): 504-10.

21. Garner JS. The CDC hospital infection control practices advisory committee. Am $\mathrm{J}$ infect control 1993; 21: 160-2.

22. Piper JM, Newton ER, Berkus MD, Peairs WA. Meconium: a marker for peripartum infection. Obstet Gynecol 1998 May; 91(5 Pt 1):741-5. 